\title{
A Classical Control Approach to the Power Management of an All- Electric Hybrid Vehicle
}

Author

James Marco ${ }^{1}$, Nicholas D Vaughan

Department of Automotive Engineering, School of Engineering, Cranfield University, Cranfield, Bedfordshire, MK43 0AL, UK.

\section{Biographical Notes}

Dr James Marco

Dr Marco is a Chartered Engineer and a member of the Institute of Engineering and Technology. Dr is a Lecturer and Course Director within the Department of Automotive Engineering at Cranfield University. His research interests include real-time control, physical systems modelling and the design and analysis of automotive control and software architectures. In particular, the application of these generic and enabling technologies to the design of new energy efficient automotive technologies for hybrid electric and fuel cell vehicles.

\section{Professor Nicholas D Vaughan}

Professor Vaughan is Head of the Department of Automotive Engineering at Cranfield University. In addition to leading a number of collaborative research programmes, Professor Vaughan has been the Principal Investigator on four hybrid and fuel vehicle programmes, in which the emphasis has been on systems integration and the design of novel energy management solutions. Professor Vaughan is a Fellow of the Institution of Mechanical Engineers and was Chairman of the Automobile Division Board (2005/2006) and is on the Editorial Board for the Journal of Automobile Engineering.

\footnotetext{
${ }^{1}$ Corresponding author; j.marco@cranfield.ac.uk, +44 (0)1234 754680
} 


\section{Keywords}

Hybrid electric vehicle (HEV), systems modelling and control, power electronics, ultracapacitor.

\section{Abstract}

Modern hybrid electric vehicles (HEVs) often employ all-electric powertrains that utilise hybrid sources of power and energy; such as batteries, fuel cells and ultracapacitors. This paper describes the design, simulation and experimental verification of a power management control system that manages a high voltage battery, a DC-DC boost converter and an ultracapacitor within a front-wheel drive HEV in which the motive power for the vehicle comes from two electrical machines. As part of this study, consideration is given to the complete control system design life-cycle including plant model development, algorithm design and software implementation on the target electronic control unit (ECU). Off-line simulation and initial experimental results are presented showing the vehicle operating on a powertrain dynamometer as one means of demonstrating the ability of the ultracapacitor to limit the transient demands placed on the battery during periods of vehicle acceleration and regenerative braking.

\section{Notation}

\section{Plant Model - Electrical System Architecture}

$\begin{array}{lll}\mathrm{C}_{\mathrm{u}} & \text { Ultracapacitor capacitance } & \mathrm{F}\end{array}$

$\mathrm{i}_{\mathrm{L}} \quad$ Inductor (battery) current $\quad \mathrm{A}$

$\mathrm{i}_{\mathrm{MB}} \quad$ Bus load current from the electrical machines

L Boost converter inductor

$R_{d} \quad$ Battery discharge resistance

$\mathrm{R}_{\mathrm{i}} \quad$ Inductor resistance

$R_{u} \quad$ Ultracapacitor internal resistance

u PWM control signal

$\begin{array}{lll}V_{B} & \text { Bus voltage }\end{array}$

$\begin{array}{lll}\mathrm{V}_{\mathrm{cu}} & \text { Ultracapacitor voltage } & \mathrm{V}\end{array}$ 
$\begin{array}{lll}V_{D} & \text { Diode voltage drop }\end{array}$

$\mathrm{V}_{\mathrm{oc}} \quad$ Battery open circuit voltage $\mathrm{V}$

$\begin{array}{lll}V_{\text {sw }} & \text { IGBT switching losses } & V\end{array}$

\section{Control System}

$\mathrm{G}_{\mathrm{c}}(\mathrm{s}) \quad$ Current controller transfer function

$(-)$

$\mathrm{G}_{\mathrm{v}}(\mathrm{s}) \quad$ Voltage controller transfer function

$(-)$

$\omega_{\mathrm{cc}} \quad$ Crossover frequency - current control loop rads $^{-1}$

$\omega_{\mathrm{cv}} \quad$ Crossover frequency - voltage control loop rads $^{-1}$

$\phi_{c c} \quad$ phase margin - current control loop degrees

\section{HEV Powertrain Model}
$A_{v} \quad$ Vehicle cross sectional area
$\mathrm{m}^{2}$
$\mathrm{C}_{\mathrm{r}} \quad$ Coefficient of rolling resistance
$\mathrm{C}_{\mathrm{w}} \quad$ Vehicle drag constant
g Gravitational constant
$\mathrm{ms}^{-2}$
$\mathrm{F}_{\mathrm{e}} \quad$ Environmental force
$\mathrm{N}$
$\mathrm{i}_{\mathrm{m}} \quad$ Machine current
A
$\mathrm{k}_{\mathrm{m}} \quad$ Machine torque constant
$\mathrm{NmA}^{-1}$
$\mathrm{L}_{\mathrm{m}} \quad$ Machine inductance
$\mathrm{H}$
$M_{v} \quad$ Vehicle mass
$\mathrm{kg}$
$R_{m} \quad$ Machine armature resistance
$\Omega$
$r_{v} \quad$ Wheel radius
$\mathrm{m}$
$V_{m} \quad$ Machine terminal voltage
V
$v_{v} \quad$ Vehicle velocity
$\mathrm{ms}^{-1}$
$\tau_{\mathrm{m}} \quad$ Machine torque
$\mathrm{Nm}$
$\omega_{\mathrm{m}} \quad$ Machine rotor velocity
$\operatorname{rads}^{-1}$ 


\section{Terms and Abbreviations}

CAN Controller Area Network

EMFR Electrical Machine Front Right

EMFL Electrical Machine Front Left

ESR Effective Series Resistance

EV Electric Vehicle

HEV Hybrid Electric Vehicle

HVBC High Voltage Bus Controller

INST Instrument Panel

ICE Internal Combustion Engine

IGBT Insulated Gate Bipolar Transistor

PMS Power Management System

PPS Peak Power Source

RTW Real-Time Workshop

SES Steady-State Energy Source

SOC State of Charge

VSC Vehicle System Controller 


\section{Introduction}

The development of hybrid electric vehicles (HEVs) is an active area of research for a number of automotive manufacturers, subsystem suppliers and academic institutions worldwide. In order to ascertain the most cost-effective and innovative solution, researchers are concurrently investigating different powertrain architectures, different hybridisation strategies and the integration of different subsystem technologies (Emadi et al., 2005).

The term HEV has historically become sin ominous with powertrain architectures that comprise an internal combustion engine (ICE) and one or more electrical machines. Such powertrains are mainly classified as being either parallel, series or complex. In recent years, new powertrain variants such as; plug-in hybrids and through-the-road hybrids have been attracting interest from both the academia and industry (Harrington et al., 2008).

If the term HEV is used in its most generic sense, in addition to those powertrain topologies that employ an ICE, it will also encompass all-electric powertrains that utilise hybrid sources of power and energy. For example, considerable attention has been given to the integration of fuel cells, batteries and ultracapacitors. The difference between each topology relates mainly to whether the primary source of energy is a fuel cell (Gao et al., 2005, Suh and Stefanopoulou, 2006) or a battery (Ozatay et al., 2004) and to the degree and location of the power electronics within the powertrain; in particular, whether the main vehicle bus voltage is held at a constant value (Lidozzi, 2004) or allowed to vary with the terminal voltage of the ultracapacitor (Suh and Stefanopoulou, 2006). Irrespective of the exact nature of the technology and architecture employed, one subsystem is generally used as a steadystate energy source (SES) and the other a peak power source (PPS).

Critical to realising the objective of an energy efficient HEV is the design of a control system for the vehicle's electrical architecture that properly allocates power between the SES and the PPS. The subject of energy management for HEVs has been widely reported within the literature with methods broadly classified as being either off-line or on-line (Cacciatori, 2007). Off-line control methods, such as Dynamic Programming, are not suitable for real-time applications because they need priori knowledge of the driving schedule and in many cases require a prohibitive computational load to be placed on the vehicle's electronic control unit (ECU) (Brahma, 2000, Lin 2001). However, they can be used to better understand the global optimal solution and highlight potential rules for inclusion within a real-time controller. On-line methods such as a heuristic rule-based control and cost function 
minimisation, possibly as part of an equivalent fuel consumption strategy, are suitable for real-time applications (Pisu and Rizzoni, 2007). Because of their inherent structure they are known to produce sub-optimal solutions (Cacciatori, 2007), but have the advantage that they are relatively easy to understand, implement and calibrate.

Given the multidisciplinary nature of HEV development, coupled with the demanding challenge of evaluating different vehicle architectures, and subsystem technologies, it is important that the control system be easy to understand and extend by non domain experts. In this regard, it can be argued that classical control methods have an advantage since many engineers, even those without a formal control engineering background, understand the basic functions of a PID feedback controller and are able to obtain satisfactory system performance through calibration. Furthermore, control systems based on PID approaches are already widely employed within the automotive sector by practicing engineers and calibrators and can be easily implemented using low cost control hardware to demonstrate proof-of-concept for a particular vehicle and/or energy storage subsystem.

The aim of this paper is to present a classical control approach for the integration of a HEV that employs a high voltage battery as the steady state energy source in parallel with an ultracapacitor acting a power-buffer or peak power source. The control objectives are to regulate the state of charge (SOC) of the PPS and to limit the rate and absolute magnitude of the demand placed on the SES. The prototype vehicle is a front-wheel drive HEV in which the motive power for the vehicle comes from two electrical machines; one machine being directly coupled to each drive wheel. A DC-DC boost converter is employed to de-couple and manage the flow of power between the SES and PPS. The complete design life-cycle is presented for the classical control solution, including plant model development, algorithm design, software implementation and finally experimental verification. Both the simulation and the initial experimental results highlight the ability of the ultracapacitor to reduce the transient load that is placed on the SES. This paper extends a previous simulation-based study (Marco and Vaughan, 2008) in which a similar control scheme was presented for a HEV employing a fuel cell and ultracapacitor, where the aim was to investigate the ability of the ultracapacitor to prevent oxygen starvation within the fuel cell.

This paper is structured as follows; Section 2 provides an overview of the vehicle control architecture for the HEV. Section 3 introduces the design of the classical control system that will be used to facilitate the initial proof-of-concept study into the HEV and the integration of its subsystems. Section 4 , presents off-line simulation and experimental test results that verify the operation of the control 
system and the fidelity of the HEV powertrain model. Experimental results demonstrate the ability of the control system to manage the SOC of the PPS when the HEV is operating on a powertrain dynamometer and subject to a transient acceleration and braking schedule. Finally, within Section 5 a critical review of the electrical architecture for the HEV is presented. Consideration is given to the calibration and complexity of the proposed control system and also the implications of the topology on the sizing of the PPS for automotive applications.

\section{Vehicle Control Architecture}

Figure 1 provides an overview of the control architecture for the HEV. As it can be seen, it consists of five ECUs connected via two controller area networks, or CAN buses. Each CAN bus operates at a baud-rate of $500 \mathrm{kbs}^{-1}$. The control functionality, as within a production vehicle, is structured hierarchically and distributed throughout the different ECUs. The allocation of control functionality to each ECU was done either on the basis of improving the efficiency of the development team or to ensure the real-time operation of the communication network. For example, the switching frequency of the power electronic subsystems on the vehicle are in the order $20 \mathrm{kHz}$; distributing the feedback control systems for the power electronics would therefore place a prohibitive load on the CAN bus and potentially result in non-deterministic behaviour. The highest level of control authority within the vehicle is the Vehicle System Controller (VSC). The four primary features of the VSC are summarised in Table 1. The power management functionality for the vehicle resides, in-part, within the VEC feature and also within the High Voltage Bus Controller (HVBC).

\section{Control System Design}

\subsection{Plant Model Development}

The design of simulation models that represent both the dynamics of the vehicle and it's electrical architecture is a challenging task; such models are highly non-linear, stiff and execution of the model states is often not only a function of time but also of discrete events (Marco, 2008, Marco and Cacciatori, 2007). As a result, a fundamental understanding of the dynamics of the system is a prerequisite to accurate numerical simulation and control system design.

The following subsections derive the state and algebraic equations that characterise the dynamic behaviour of the vehicle's electrical architecture. The equivalent electrical circuit for the vehicle's high voltage system is presented in Figure 2. The circuit comprises of a high voltage battery, a DC-DC boost converter and an ultracapacitor connected in parallel to the output stage of the power 
electronics. It is envisaged that the architecture will potentially be deployed within two further vehicles; one employing a fuel cell instead of the battery and another in which a plug-in recharge capability is added to the vehicle to main the SOC of the battery pack. As a result, of particular interest to this study is the ability of the ultracapacitor to act as a power-buffer to the battery and therefore only the discharge characteristics of the battery are considered with the ultracapacitor SOC being managed both via the battery and through regenerative braking.

The high voltage battery; a $130 \mathrm{~V}$ lead acid battery pack, represents the steady-state energy source for the vehicle. The battery was modelled via an equivalent electrical circuit comprising an ideal open circuit voltage $\left(V_{o c}\right)$ in series with a discharge resistance $\left(R_{d}\right)$. The values of $R_{d}$ and $V_{o c}$ were obtained experimentally and are both non-linear functions of the batteries SOC. Because the primary aim of the model is to study both transient driving events and the energy consumption of the powertrain, the additional parallel resistance term often used to describe the self-discharge characteristics of the battery, as described in (Jackey, 2007) was omitted from the model.

A comprehensive review of the different types of power electronic models and their applications is provided in (Maksimovic et al., 2001) . Figure 2 presents a small-signal, averaged model of a DC-DC boost converter. The power electronic switching device, an Insulated Gate Bipolar Transistor (IGBT), is replaced by a continuous-time control signal, $u(t)$ with the constraint; $0 \geq u(t) \leq 1$. As shown in (Lu et al., 2004, Maksimovic et al., 2001) the conduction losses associated with the IGBT and the power diode are represented by a constant reverse voltage $\left(V_{D}\right)$ within the circuit. The switching losses $\left(V_{\mathrm{sw}}\right)$ are represented as a non-linear function of the inductor current and are derived from the manufacturer's literature for the device. Results presented in (Maksimovic et al., 2001) show that converter dynamics up to approximately one-tenth of the switching frequency of the IGBT are accurately captured by a model of this type. Since the switching frequency for the IGBT is in the order $20 \mathrm{kHz}$, the simplified model is deemed to be sufficiently representative for automotive control system design purposes. For the purpose of this study the output smoothing capacitor from the boost converter is neglected, since its value is many orders of magnitude less than that of the ultracapacitor and therefore its dynamics are considerably faster.

An accurate model of the complete ultracapacitor subsystem can be obtained from a first-order resistor-capacitor circuit, where $C_{u}$ defines the total capacitance of the ultracapacitor and $R_{u}$ the effective series resistance (ESR) of the ultracapacitor (Amrhein and Krein, 2005, Cegnar et al., 2004, 
Liqing et al., 2004). As with the high voltage battery model, incorporating the self-discharge effects of the ultracapacitor was not deemed to be within the scope of the simulation.

From the equivalent model of the electrical bus system presented in Figure 2 and from the description of the different subsystems, given above, it can be seen that the electrical architecture of the vehicle has two states and can be represented by the following bilinear, first-order differential equations

$$
\begin{aligned}
& \frac{d i_{L}}{d t}=\frac{1}{L}\left[V_{o c}-i_{L} \cdot\left(R_{d}+R_{i}\right)-(1-u) \cdot V_{B}-V_{D}-V_{s w}\right] \\
& \frac{d V_{c u}}{d t}=\frac{1}{C_{u}}\left[(1-u) \cdot i_{L}-i_{M B}\right] \\
& V_{B}=V_{c u}+R_{u}\left[(1-u) \cdot i_{L}-i_{M B}\right]
\end{aligned}
$$

The term; $\mathrm{i}_{\mathrm{MB}}$ denotes the load current from the electrical machines reflected onto the high voltage bus. The fastest resonant mode within the model is that associated with the input dynamics to the boost converter. At a frequency, $\omega_{L} \cong 850 \mathrm{rads}^{-1}$, the numerical stability of the simulation can be maintained when the model is executed using a $1 \mathrm{~ms}$ fixed-step first order Euler integration algorithm. A fixed step rather than a variable step / variable order algorithm was employed to ensure that the proposed simulation model could support future real-time simulations and possible hardware-in-theloop control system verification activities. In addition, a model bandwidth of this magnitude facilitates efficient simulations for the purpose of studying both transient vehicle events such as acceleration and braking and also for predicting the vehicle's energy efficiency real-world and legislative drive-cycles.

\subsection{Control Algorithm Design}

Figure 3 presents the structure of the classical control system for managing the current flow within the HEV. As it can be seen, the control functionality is distributed between two ECUs and comprises of two nested control loops; a faster inner current loop and a slower outer voltage control loop. The load current that is required by the electrical machines act as an external disturbance to the outer loop.

\subsubsection{Design of the Current Control Loop}

For the operating points defined in Table 2, the bi-linear set of equations were linearised in order to ascertain the operating envelope for HEVs electrical system. The system can be characterised as a; Type 0 , stable system with a crossover frequency, $\omega_{c c} \cong 1.1 \times 10^{4} \mathrm{rads}^{-1}$, a phase margin, $\phi_{\mathrm{cc}} \cong 90^{\circ}$ and a gain margin of infinity. 
The design objective for the current control loop is to control the boost converter with a $10 \mathrm{kHz}$ sample frequency and for there to be negligible steady-state error in response to a step input. In order to meet these objectives, a proportional + integral $(\mathrm{P}+\mathrm{l})$ algorithm was added to the forward path dynamics. Design of the control strategy was based on the frequency response for the system with the lowest steady-state gain, as this represented the worst-case operating point with respect to the design objectives. Parameterisation of the algorithm was an iterative process and involved the graphical interpretation of the system dynamics. In addition to $G_{c}(s)$, a saturation is also added to the forward path of the control loop such that, in accordance with the definition of $u(t)$, the control signal is bound between zero and unity. Anti-windup compensation was added to the integral control term to prevent instability of the control loop due to possible saturation of the controller demand signal.

By including the $\mathrm{P}+\mathrm{l}$ algorithm it can be seen that the system has been transformed to a Type I, resulting in an increase in low-frequency gain. Both the phase margin and gain margin of the system are unchanged, however $\omega_{c c}$ has been reduced in value to that, which facilitates the desired sample frequency.

Equation (4) presents the software implementation form of the $\mathrm{P}+\mathrm{I}$ algorithm after it has been digitised using the Backward Euler pole-matching approximation technique.

$$
G_{C}(s)=\left.\frac{K_{p c} \cdot s+K_{l c}}{s}\right|_{s \rightarrow \frac{K \cdot T_{s}}{1-z^{-1}}} \Rightarrow G_{C}(z)=\frac{K_{p c} \cdot K \cdot T_{s}+K_{l c}\left(1-z^{-1}\right)}{K \cdot T_{s}} \mid
$$

\subsubsection{Design of the Voltage Control Loop}

Figure 5 presents the uncontrolled and compensated open-loop dynamics of the transfer function relating the battery current to the vehicle bus voltage. Since any large voltage transients above the upper limit would potentially damage both the power electronic switch and also the individual cells that comprise the ultracapacitor, the primary control objective for the voltage loop is for it to be over or critically damped. In addition, the bandwidth of the voltage control loop should be sufficiently low so as to ensure that the two nested loops do not detrimentally interact with one another and the real-time performance of the CAN bus is deterministic.

The same general procedure that was introduced in section 3.2.1 was employed to design the algorithm for the voltage control loop. However $G_{v}(s)$ was constrained to be a proportional only controller in which the value of gain is bound between an upper and lower limit. From Figure 5, it can 
be seen that the compensated dynamics result in the voltage control loop having a low frequency gain in the order or $10 \mathrm{~dB}$ and a crossover frequency, $\omega_{\mathrm{cv}} \cong 0.6 \mathrm{rads}^{-1}$. The primary reason for the use of proportional control is that the dynamics of the ultracapacitor result in a pole very close the origin of the s-domain, which means that the system inherently contains integral corrective action. In addition, the use of proportional control results in a system that can be very easily calibrated as one method of changing the operating characteristics of the vehicle. Initial calibration of $G_{v}(s)$ was done using off-line simulation with both the linear and non-linear circuit models. The digitisation of the voltage control loop was done using a Backward Euler pole-matching approximation technique and with a sample frequency of $20 \mathrm{~Hz}$.

\subsection{Off-line Verification of the Control System}

In order to verify the operation of the plant model and the associated control algorithms a series of offline simulations were conducted. A full HEV powertrain model was derived so that representative electrical loads could be defined and applied to the control system. The ability to exercise the control system against a more representative non-linear model of the vehicle also facilitated further off-line calibration of the controller gains for $G_{v}(s)$ and $G_{c}(s)$.

Figure 6 presents the free-body diagram for the powertrain. The powertrain comprises of two torque controlled electrical machines directly coupled to each of the front wheels. A steady-state representation of the inverter drive for each of the machines is used which characterises the subsystem efficiency as a function of the conduction and switching power losses of the IGBTs. The vehicle body is represented as a single lump parameter of mass in which the force from the electrical machines and the external environment acts directly through the centre of gravity. The model is a simplified version of that contained in (Marco et al., 2007). A full derivation of the model, including the aims, objectives and assumptions made during the model development process are presented in (Marco et al., 2007) and will therefore not be repeated here. Instead, only the pertinent state and algebraic equations that describe the dominant dynamics of the system are provided below.

$$
\begin{aligned}
& \frac{d_{i_{m}}}{d t}=\frac{1}{L_{m}}\left[\left(\alpha \cdot v_{m}\right)-\left(k_{m} \cdot \varpi_{m}\right)-\left(i_{m} \cdot R_{m}\right)\right] \\
& \tau_{m}=k_{m} \cdot i_{m}
\end{aligned}
$$




$$
\begin{aligned}
& i_{M B}=\sum \frac{2 \cdot\left(\left|i_{m} \cdot v_{D}\right|+p_{\text {switch }}\right)}{v_{C u}} \\
& \frac{\mathrm{d} v_{\mathrm{v}}}{\mathrm{dt}}=\frac{1}{\mathrm{M}_{\mathrm{v}}}\left(\cdot \frac{1}{r_{\mathrm{v}}}\left(\tau_{\mathrm{mr}}+\cdot \tau_{\mathrm{mf}}\right)-\mathrm{F}_{\mathrm{e}}\right) \\
& F_{e}=\left[M_{v} \cdot g \cdot C_{r} \cdot \operatorname{sign}\left(v_{v}\right)\right]+\left[M_{v} \cdot g \cdot \sin (\alpha) \cdot \operatorname{sign}\left(v_{v}\right)\right]+\left(\frac{1}{2} \rho \cdot C_{w} \cdot A \cdot v_{v}{ }^{2}\right)
\end{aligned}
$$

The variables for each of the above equations are defined at the beginning of this paper with a more detailed description in (Marco et al., 2007). The simulation results of the off-line verification process are not presented in isolation, but a sample are discussed in Section 4 and compared to the experimental results obtained from the actual vehicle.

\subsection{Hardware Implementation of the Control System}

The aim of this section is to briefly introduce the hardware implementation of the VSC and those parts of the power management system that reside within it. The VSC was implemented using automatic code generation techniques to the target hardware. The advantages associated with this design methodology are well known and widely reported within the literature (Lefartha et al., 1998, Yamazaki et al., 2002).

The VSC control algorithms, both supervisory and feedback, were implemented within the Mathworks tool-set; Matlab, Simulink and Stateflow. The model therefore formed an executable specification for the control system. Figure 8 presents the high-level structure of the VSC control model in Simulink. The control functionality is encapsulated within the Core Application subsystem and is therefore largely independent of the input-output interfaces for the controller. Real-time execution of the VSC employed the rate-monotonic, pre-emptive, multitasking scheduler associated with Simulink and the Real-Time Workshop (RTW). The use of a multitasking rather than a single-tasking operating system allows for greater flexibility and improved run-time efficiency of the ECU's resources.

The ECU employed for this investigation was a propriety system, the architecture of which is described fully within the Manufacturer's literature. Table 3 summarises the hardware utilisation of the VSC when operating on the ECU. 


\section{Experimental Validation of the Power Management Control System}

In order to validate the integration of the prototype vehicle, the proposed control architecture and the functionality of the electromechanical and energy storage subsystems, experiments were conducted on the rolling chassis of the HEV. The vehicle was coupled to a powertrain dynamometer within the University. Unlike a conventional chassis rolls type dynamometer, this dynamometer employs two electrical machines that are connected directly to the front drive wheels. Each machine is rated at $290 \mathrm{~kW}$ and is capable of delivering $2200 \mathrm{Nm}$. For the purpose of the experimental work discussed below, the dynamometer was operated in road-law mode. Within this mode of operation, the dynamometer emulates the both the inertia of the vehicle and the external torques acting on the vehicle due to both rolling resistance and aerodynamic drag. The simulation model presented in Section 3.3 was employed to generate the coast-down curve for the vehicle from an initial speed of $125 \mathrm{kmh}^{-1}$. Once this characteristic curve had been programmed into the dynamometer, the equipment was then calibrated to compensate for internal losses within the electromechanical drive system, thereby ensuring the accurate emulation of the physical vehicle operating within the external environment.

A number of tests were conducted on the vehicle relating to both the start-up and shutdown sequencing of the HEV, the dynamic performance of the electromechanical powertrain and also verifying the correct management of the various failure modes in the system.

Two test programmes that relate directly to the power management control system are described below; the first aims to validate the set-point response of the power management control system and the second to validate the disturbance rejection characteristics of the proposed control strategy.

\subsection{Set-Point Response}

For proper operation of the vehicle, the set-point response of the voltage control loop is important. The control system must be able to track a change in the set-point. This test scenario represents the use case in which an energy transfer between the SES and the PPS is required. For example, before the vehicle is first driven it may be deemed that the ultracapacitor must be pre-charged from the battery or fuel cell. Experimental tests conducted in support of this project have identified that the stored energy within an ultracapacitor will considerably reduce, due to self-discharge, over a 24 to 48 hour period.

Figure 8 shows both the experimental response and the simulated response of the power management control system to two step-changes in the set-point applied to the voltage control loop. 
The test commences with the ultracapacitor charged to approximately $300 \mathrm{~V}$. At a time $t=16 \mathrm{~s}$ and $\mathrm{t}=$ 80 s the set-point is increased to $330 \mathrm{~V}$ and $350 \mathrm{~V}$ respectively, representing an overall increase of $55 \%$ in the SOC of the PPS. As it can be seen, there is a high degree of correlation between the experimental results and those predicted by the simulation model, even when the ultracapacitor voltage is away from the point of linearisation. The Figure also shows the current drawn from the battery in order to raise the SOC of the ultracapacitor. For low values of current, the reason for the discrepancy between the actual and predicted values is due to dead-band within the current sensor employed as part of the DC-DC boost converter.

\subsection{Disturbance Rejection Characteristics}

As discussed in Section 3.2, current is drawn from the ultracapacitor to support vehicle acceleration resulting in a reduction in the DC link voltage within the vehicle. Conversely, during periods of regenerative braking, a portion of the kinetic energy of the vehicle is converted into electrical energy and stored in the ultracapacitor, thereby causing the bus voltage to rise. The load current from the electrical machines therefore act as an external disturbance to the voltage control loop that regulates the SOC of the ultracapacitor.

Figure 9 shows the response of the vehicle to a series of tip-in/out acceleration events. There are also two regenerative braking events; one at a time $t=160 \mathrm{~s}$ and one at a time $t=330 \mathrm{~s}$. The torque demand shown was applied to the powertrain dynamometer and also to the vehicle simulation model presented earlier within this paper. The resulting vehicle speed profile measured from the powertrain dynamometer correlates well with that predicted by the powertrain model presented in Section 4 . However, it should be noted that in order to achieve this correlation an additional loss torque term was applied to the simulated vehicle mass, thereby reducing the net applied torque acting on the vehicle. This vector represents un-modelled parasitic losses that are not present within the original mathematical equations.

For a torque demand of $70 \mathrm{Nm}$, the vehicle reaches a speed just in excess of $100 \mathrm{kmh}^{-1}$. The rate of vehicle acceleration and deceleration is in the order of $0.15 \mathrm{~g}$ and is therefore representative of that found within a number of urban drive-cycles, such as the European ECE-15 and the North American cycle UDDS.

Throughout the cycle, the voltage control loop attempts to maintain a constant value of $270 \mathrm{~V}$. However, under transient load conditions this is not possible since the ultracapacitor is required to 
buffer the battery and reduce the rate and magnitude of current that is required from the steady-state energy device. It is only when the vehicle tends to a constant speed, at a time $t>450$ s, does the value of bus voltage re-stabilise at the desired value, since all the cruise energy required for the vehicle is provided by the high voltage battery.

The transition between vehicle acceleration and cruise is accommodated for within the SISO control strategy without the need for any further supervisory rules. With reference to Figure 2 and Equations (1) - (4), it can be seen that for a constant load current, the system will reach an equilibrium point in which all of that energy is provided by the battery. Furthermore, if the SOC of the ultracapacitor is above the desired value for a give speed, the negative error within the control loop is rounded to zero thereby automatically reducing the probability of an over voltage condition within the ultracapacitor, since for as long that conditions exists the ultracapacitor will meet all of the load current. The two control modes discussed above are inherently catered for by the structure of the SISO control system do no further supervisory rules or states are required within the controller. This has this advantage that it further reduces the calibration requirements for the implementation of the power management system within a prototype vehicle.

For this particular investigation the target voltage of the ultracapacitor was set to $270 \mathrm{~V}$, since this value lies within the centre of the normal operating range of the ultracapacitor. As a result, the device has sufficient SOC to assist in the acceleration of the vehicle and also enough capacity for storing energy from regenerative braking events.

\section{Discussion}

The aim of this section is to highlight the relative merits and shortcomings associated with the HEV electrical architecture presented in Figure 2. The discussion focuses on three main areas;

- $\quad$ sizing of the PPS,

- the associated control system complexity that is required to manage the system and finally,

- $\quad$ the calibration and range prediction of the HEV powertrain over legislative drive-cycles.

\subsection{Sizing of the PPS subsystem}

The need for the PPS to connect directly to the high voltage bus means that, for a given cell technology, the size of the PPS is fixed. The long string length may also result in a value of mass and volume that may in turn prohibit its integration within certain classifications of vehicle. For an 
ultracapacitor, cell voltages in the order of $2.7 \mathrm{~V}$ are common, which implies that a for $\mathrm{DC}$ bus voltage in the order $400 \mathrm{~V}$ a string length of 160 cells is required. Large string lengths, such as this, require balancing of the cells to ensure that the performance of the pack does not degrade. For the PPS discussed within this paper balancing resistors were required between each of the ultracapacitor cells to prevent divergence of the individual voltages. Furthermore, the ultracapacitor was structured using modules of eight cells and additional instrumentation was integrated so that the VSC could manage the temperature and voltage of each module.

An alternative to the electrical architecture presented Figure 2, is a fixed bus architecture in which a bidirectional DC-DC converter is employed in series with the PPS to maintain a constant value of bus voltage for all transient load conditions. The additional power electronics decouple the string length from the value of bus voltage. Decoupling the PPS from the DC link voltage has the advantage that it facilitates the design optimisation of the both the SES and the PPS, which may in turn result in a comparative reduction in powertrain volume and mass. However, when performing such a comparison, consideration must also be given to the mass and volume of not just the PPS and SES, but also the additional power electronics and the associated cooling systems required for their operation. Ongoing research within the University is currently investigating the application of formal optimisation techniques in which the objective is a hybrid power-energy system that minimises the energy utilisation of the powertrain while still delivering acceptable levels of vehicle driveability.

\subsection{Control System Complexity}

One of the main advantages of the electrical architecture presented within this paper is the simplicity of the control solution for the power management system. Since there is only one power electronic device, the system is inherently single-input-single-output (SISO) and therefore the use of classical control techniques are highly applicable. With simple proportional control for the outer voltage control loop, both off-line simulation and experimental studies have highlighted that the system can be easily calibrated; with the characteristics of the powertrain control strategy being varied from that of a loadfollower to a load averaging approach siply by varying the magnitude of $G_{v}(s)$.

When considering the control of a fixed bus electrical architecture, as discussed in (Marco, 2008), the additional power electronics result in increased control system complexity. In general, for each power electronic switch at least one feedback control loop is required. In some cases two nested feedback loops; an outer voltage (or SOC) control loop and an inner current control loop is necessary. 
Furthermore, in order to generate the set-point to the control loops, some form of feed-forward or model predictive control (MPC) is often required. Because of the increased number of control loops and interacting controller gains, (Marco, 2008) describes how the calibration of the overall strategy is a much more challenging task than that associated with Figure 2.

\subsection{HEV Powertrain Efficiency and Vehicle Range}

Based on the validated powertrain model and the power management control system, it is possible to investigate the energy consumption of the vehicle over different drive-cycles. Because of the time associated with the different drive-cycles, there are obvious advantages with basing this study on an off-line simulation model rather than trying to perform all of the test scenarios on the physical vehicle (especially when considering the time that would be required between dynamometer tests for reconditioning of the battery system so as to ensure that each experiment was comparable).

Figure 10 presents an example set of simulation results for the HEV over the North American UDDS drive-cycle. The figure shows the SOC of the high voltage battery, the SOC of the ultracapacitor and the three current profiles on the DC bus. Experimentation with the simulation model shows that the range of the HEV is largely unaffected by the calibration of $G_{v}(s)$ within the voltage control loop. These results are supported by other studies presented within the literature (Gao et al., 2003, Suh and Stefanopoulou, 2006) in which the ultracapacitor is employed as a source of power and not energy. By means of a comparison, Figure 11 shows the characteristics of an equivalent pure electric vehicle $(E V)$ in which the battery system is the only source of both energy and power. The corrections made to the model to enable the comparison include; increasing the size of the battery pack inline with the vehicle's power demand, but removing from the model the weight associated with the PPS. From Figure 11, it can be seen that the energy requirements are largely unchanged over the drive-cycle; however through hybridisation the transient demand placed on the battery is considerably reduced. Reducing the transient load on the SES is known to improve the operating life of certain battery technologies $\left(^{*}\right)$ nd also, if the SES is a fuel cell, reduce the probability that oxygen starvation of the fuel cell stack may occur (Suh, 2006).

\section{Conclusions}

In addition to ICE based powertrains, the generic use of the term HEV also encompasses all-electric powertrains that utilise hybrid sources of power and energy; such as integrated batteries, fuel cells and ultracapacitors. There is considerable research at present investigating the different electrical 
architectures and control system options associated with their use and integration within an automotive environment. Irrespective of the technology employed, when hybridisation occurs, one subsystem is generally employed as a source of energy and the other a source of power.

Presented within this paper is the modelling, control system design and experimental verification of a HEV that employs a high voltage battery as the SES and an ultracapacitor as a PPS. The electrical architecture employs a DC-DC boost converter to manage the energy transfer between the battery and the ultracapacitor.

Experimental analysis was conducted using the physical HEV connected to a powertrain dynamometer. The results of this experimentation showed a satisfactory level of correlation between the controlled simulation model of the HEV and the real vehicle. As a result, the model was deemed representative so as to facilitate further off-line simulation studies into vehicle efficiency and range. For the architecture selected it was identified that hybridisation of the SES does not directly improve the range of the vehicle. Hybridisation does however limit the transient demand placed on the SES, which can improve the cycle life of the SES and help limit the ancillary requirements for vehicle integration.

The control system design for the prototype HEV is based on SISO design techniques and is made up of an inner current loop and an outer voltage control loop. The advantage of a control system based on classical design methods relates primarily to the relative ease in which the controller can be calibrated and implemented using standard low-cost electronic hardware. 


\section{Acknowledgements}

The research presented within this paper forms part of the following programmes; LIFECar which is part funded by the DTI through the Technology Partnership Programme and WREN which is wholly funded by the Engineering and Physical Science Research Council (EPSRC). 


\section{References}

1. AMRHEIN, M. \& KREIN, P. T. (2005) Dynamic Simulation for Analysis of Hybrid Electric Vehicle System and Subsystem Interactions, Including Power Electronics. IEEE Transactions on Vehicular Technology, , 54, 825-836.

2. CEGNAR, E. J., HESS, H. L. \& JOHNSON, B. K. (2004), A Purely Ultracapacitor Energy Storage System Hybrid Electric Vehicles Utilizing a Based Dc-Dc Boost Converter, 19th IEEE Applied Power Electronics Conference and Exposition, APEC'04, Anaheim, California, USA, 22nd-26th February,1160-1164 vol.2.

3. EMADI, A., RAJASHEKARA, K., WILLIAMSON, S. S. \& LUKIC, S. M. (2005) Topological Overview of Hybrid Electric and Fuel Cell Vehicular Power System Architectures and Configurations. IEEE Transactions on Vehicular Technology, 54, 763-770.

4. GAO, L., DOUGAL, R. A. \& LIU, S. (2003), Active Power Sharing in Hybrid Battery/Capacitor Power Sources, 18th IEEE Applied Power Electronics Conference and Exposition, APEC '03, Florida, USA, 9th-13th February 497-503 vol.1.

5. GAO, W., NEEMA, S., GRAY, J., PICONE, J., PORANDLA, S., MUSUNURI, S. A. \& MATHEWS, J. (2005), Hybrid Powertrain Design Using a Domain-Specific Modeling Environment, IEEE Conference on Vehicle Power and Propulsion, Illinois Institute of Technology, Chicago, Illinois, USA, 7th-9th September,423-429.

6. JACKEY, R. A. (2007) Simple, Effective Lead-Acid Battery Modeling Process for Electrical System Component Selection. SAE Technical Paper Series, 2007-01-0778.

7. LEFARTHA, U., BAUMA, U., BECKA, T., WERTHERA, K. \& ZURAWKAA, T. (1998) An Integrated Approach to Rapid Product Development for Embedded Automotive Control Systems Control Engineering Practice, 6, 529-540.

8. LIDOZZI, A. (2004), Power Balance Control of Multiple-Input Dc-Dc Power Converter for Hybrid Vehicles, IEEE International Symposium on Industrial Electronics Ajaccio, France, 4th7th May, 1467-1472 vol. 2.

9. LIQING, S., WEI, C., LEIYAN, Y., LIANGHUI, Y., L, Y. \& S, F. (2004) Design and Analysis of Pure Electric Bus Jointly Powered by Lithium-Ion Battery and Ultra Capacitor. SAE Technical Paper Series, 2004-01-0368.

10. LU, Y. W., GUANG, F. \& YAN-FEI, L. (2004), A Large Signal Dynamic Model for Dc-to-Dc Converters with Average Current Control, Nineteenth Annual IEEE Applied Power Electronics Conference and Exposition (APEC '04) 797-803 vol.2.

11. MAKSIMOVIC, D., STANKOVIC, A. M., THOTTUVELIL, V. J. \& VERGHESE, G. C. (2001) Modeling and Simulation of Power Electronic Converters. Proceedings of the IEEE Transactions, 89, 898-912.

12. MARCO, J. (2008), Electrical Architectures for Hybrid Vehicles: Implications for Modelling and Control, Proceedings of the 2008 International Conference on Control (UKACC), University of Manchester, UK, 2008, 2nd - 4th September.

13. MARCO, J. \& CACCIATORI, E. (2007), The Use of Model Based Design Techniques in the Design of Hybrid Electric Vehicles, Proceedings of the 3rd IET International Automotive Electronics Conference, University of Warwick, UK, 28th-29th June.

14. MARCO, J. \& VAUGHAN, N. D. (2008) The Control-Oriented Design and Simulation of a High Voltage Bus Management Strategy for Use within Hybrid Electric Vehicles. International Journal of Vehicle Systems Modelling and Testing, 2, 345-368.

15. MARCO, J., VAUGHAN, N. D., SPOWERS, H. \& MCCULLOCH, M. (2007) Modelling the Acceleration and Braking Characteristics of a Fuel-Cell Electric Sports Vehicle Equipped with an Ultracapacitor Proceedings of the Institution of Mechanical Engineers, Part D: Journal of Automobile Engineering, 221, 117-133. 
16. OZATAY, E., ZILE, B., ANSTROM, J. \& BRENNAN, S. (2004), Power Distribution Control Coordinating Ultracapacitors and Batteries for Electric Vehicles, Proceedings of the 2004 American Control Conference, Boston, USA,4716-4721 vol.5.

17. SUH, K. W. \& STEFANOPOULOU, A. G. (2006) Effects of Control Strategy and Calibration on Hybridization Level and Fuel Economy in Fuel Cell Hybrid Electric Vehicle. SAE Technical Paper Series, 2006-01-0038.

18. YAMAZAKI, M., SURESHBABU, S., LOFTUS, M., CRANDELL, R. \& BRACKX, M. (2002), Analysis of Automatically Generated Vehicle System Control Software in a Hil Environment, Proceedings of the 2002 American Control Conference 3135-3140.

19. Harrington C., et al., (2008), Affordable Hybrid Electric System for Urban Commercial Vehicle Applications, using an Advanced VRLA Battery, Hybrid and Eco Friendly Vehicles Conference, University of Warwick, UK, $8^{\text {th }}-9^{\text {th }}$ December.

20. Cacciatori E., (2007)., Advanced Control Concepts for a Parallel Hybrid Powertrain with Infinitely Variable Transmission, PhD Thesis, Cranfield University, School of Engineering, UK.

21. Brahma, A., et al., (2000), Optimal energy management in series hybrid electric vehicles, American Control Conference, Proceedings of the, Chicago, IL, US, 28-30 June 2000, p. 6064

22. Lin, C. et al., (2001), Integrated, feed-forward hybrid electric vehicle simulation in SIMULINK and its use for power management studies, SAE 2001 World Congress, Detroit, Michigan, USA, 5 March 2001, 2001-01-1334 


\section{Tables}

\begin{tabular}{|l|l|}
\hline $\begin{array}{l}\text { VSC Feature } \\
\text { Acronym }\end{array}$ & Description \\
\hline VDR & $\begin{array}{l}\text { Driver Request. The single source of driver input monitoring and input fault } \\
\text { diagnostics. Transmits driver torque requests and vehicle mode requests to the rest } \\
\text { of the strategy. }\end{array}$ \\
\hline VEC & $\begin{array}{l}\text { Energy Coordinator. Primarily contains the voltage control loop of the power } \\
\text { management system. Also manages the power electronics, battery and } \\
\text { ultracapacitor subsystems. }\end{array}$ \\
\hline VMC & $\begin{array}{l}\text { Motion Coordinator. Based on the driver request and the operating conditions of the } \\
\text { vehicle, the VEC manages the torque allocation between the two electrical machines. }\end{array}$ \\
\hline VMA & $\begin{array}{l}\text { Mode Arbitration. Manages the start-up and shut down sequencing of the vehicle and } \\
\text { also the transition to failure modes (limited operating modes) under subsystem fault } \\
\text { conditions and/or driver operating error. }\end{array}$ \\
\hline
\end{tabular}

Table 1: VSC feature summary 


\begin{tabular}{|l|l|l|}
\hline \multicolumn{1}{|c|}{$\mathrm{I}_{\mathrm{A})}$} & $\mathrm{V}_{\mathrm{uc}}(\mathrm{V})$ & \multicolumn{1}{c|}{ Description } \\
\hline Low & Low & $\begin{array}{l}\text { Not a valid operating point, since it represents the vehicle travelling at } \\
\text { low load with a low output from the battery and a low value of bus } \\
\text { voltage. In reality, the battery would be used to charge the } \\
\text { ultracapacitor. }\end{array}$ \\
\hline Low & High & $\begin{array}{l}\text { A valid operating point, since it represents the vehicle travelling at low } \\
\text { speed with a low output from the battery and a charged ultracapacitor. }\end{array}$ \\
\hline High & Low & $\begin{array}{l}\text { A valid operating point, since it represents the vehicle travelling at high } \\
\text { speed with a high output from the battery and a discharged } \\
\text { ultracapacitor. }\end{array}$ \\
\hline High & High & $\begin{array}{l}\text { Not a valid operating point, since it represents a high output from the } \\
\text { battery when the ultracapacitor is fully charged. In reality stored energy } \\
\text { would be used to propel the vehicle. }\end{array}$ \\
\hline
\end{tabular}

Table 2: Operating conditions for model linearization $\left(\mathrm{I}_{\mathrm{L}} \mathrm{Low}=20 \mathrm{~A}\right.$, High $=191 \mathrm{~A} ; \mathrm{V}_{\mathrm{uc}}$ Low $=250 \mathrm{~V}$, High $=350 \mathrm{~V})$ 


\begin{tabular}{|c|c|c|c|c|}
\hline \multirow[t]{6}{*}{ ECU Resources } & \multirow[t]{2}{*}{ Memory } & $\begin{array}{l}\text { Flash Memory } \\
\text { (ROM) }\end{array}$ & RAM & $\begin{array}{c}\text { Calibration } \\
\text { Memory }\end{array}$ \\
\hline & & $234 \mathrm{~Kb}$ & $21 \mathrm{~Kb}$ & $180 \mathrm{~Kb}$ \\
\hline & \multirow[t]{2}{*}{ CPU } & $\begin{array}{l}\text { Peak CPU } \\
\text { Utilisation }\end{array}$ & $\begin{array}{c}\text { Average CPU } \\
\text { Utilisation }\end{array}$ & \\
\hline & & $48 \%$ & $32 \%$ & \\
\hline & \multirow{2}{*}{$\begin{array}{l}\text { Number of } \mathrm{I} / \mathrm{O} \\
\text { Channels }\end{array}$} & Analogue In & Digital (in/out) & PWM Out \\
\hline & & 13 & $7 / 4$ & 3 \\
\hline
\end{tabular}

Table 2: Hardware resource requirements for the VSC when operating on the target hardware 
Figures

CAN 1: Control Bus

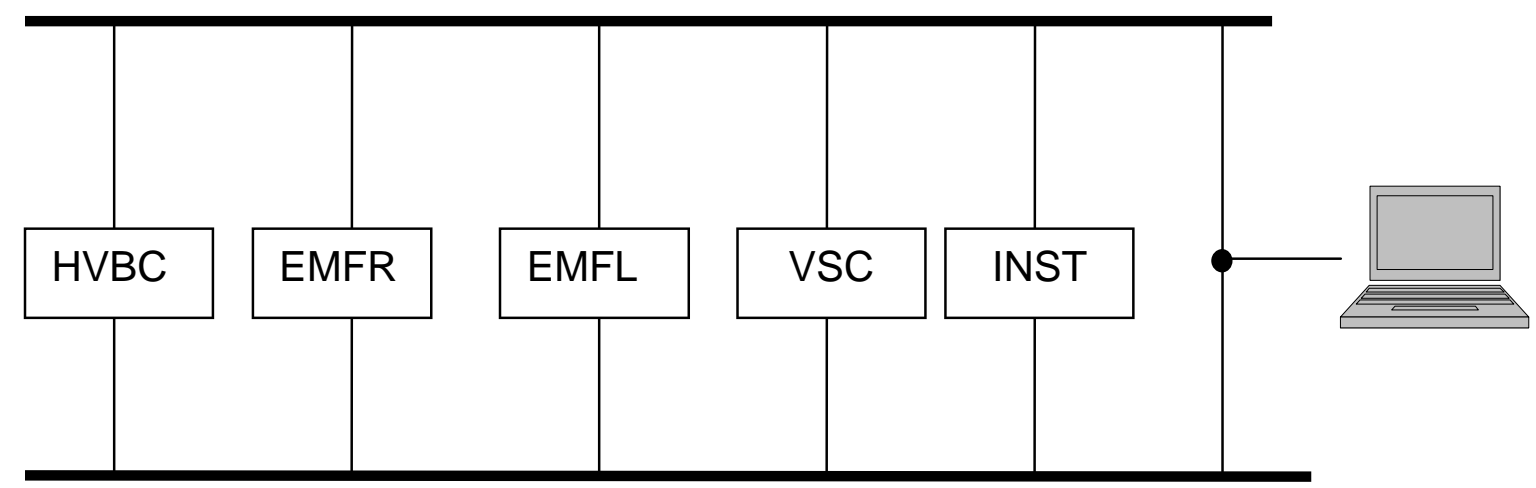

CAN 2: Diagnostics Bus

Figure 1: Distributed control architecture for the HEV 


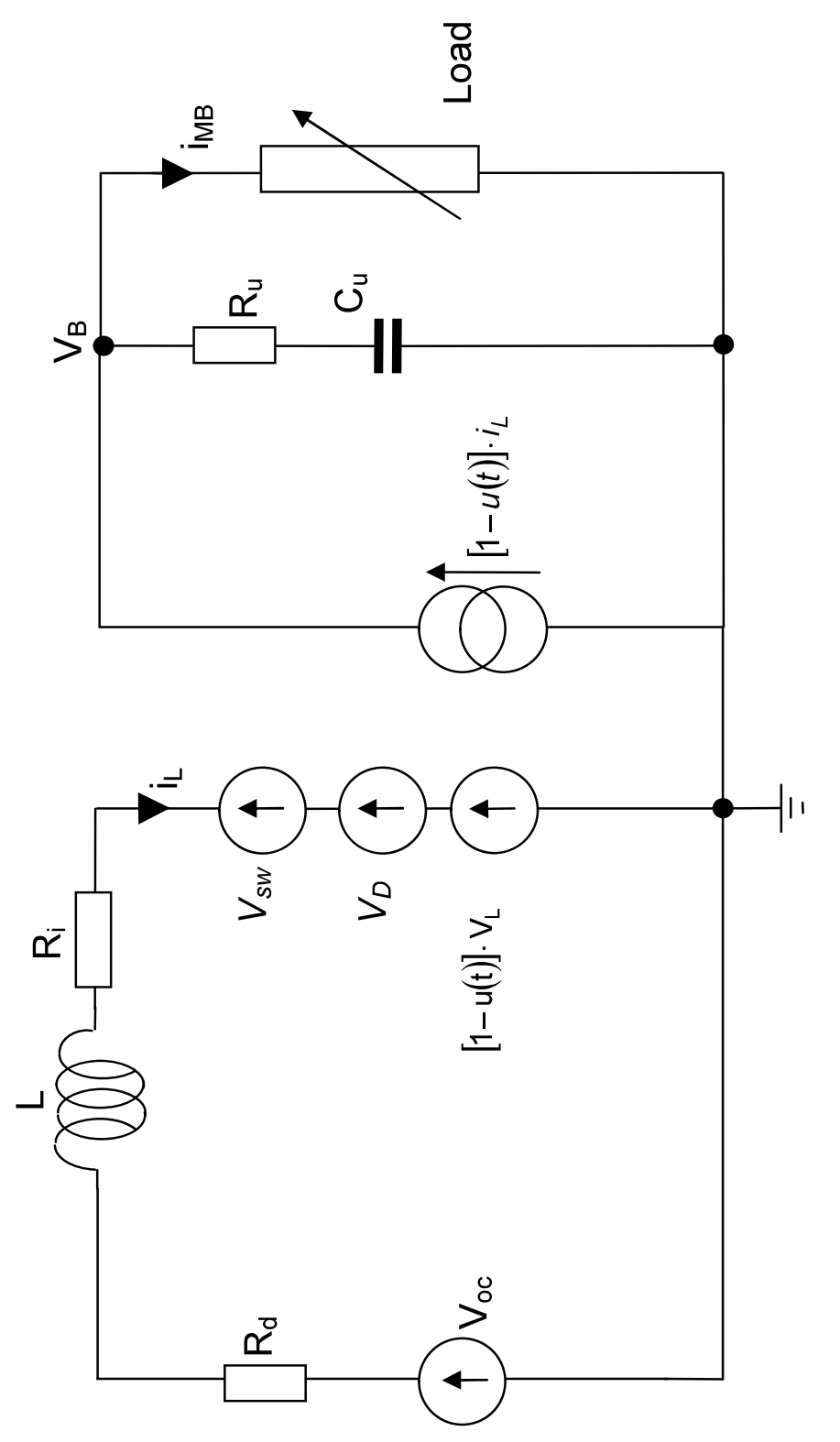

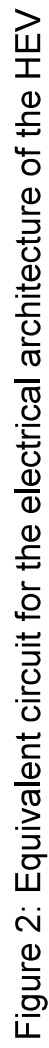




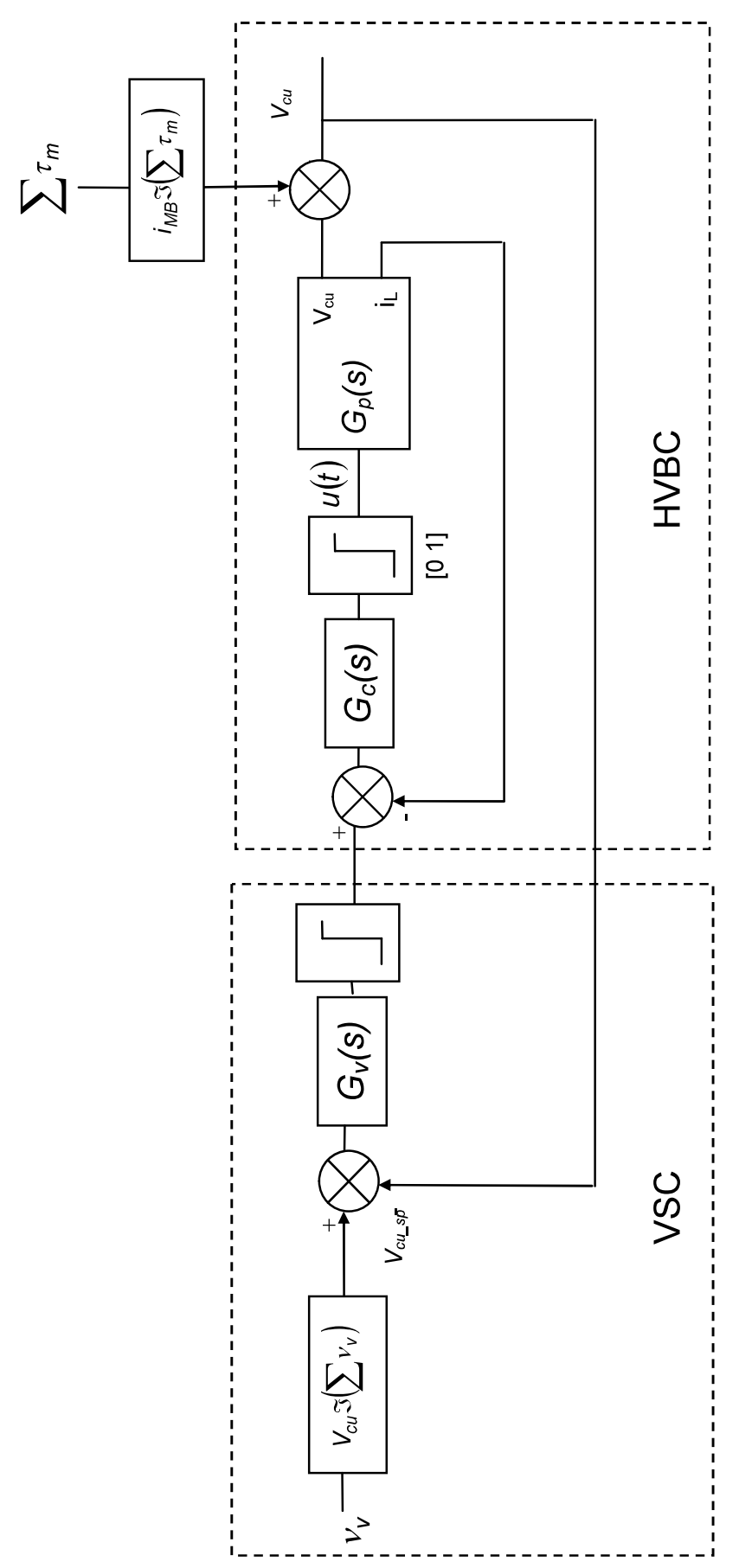



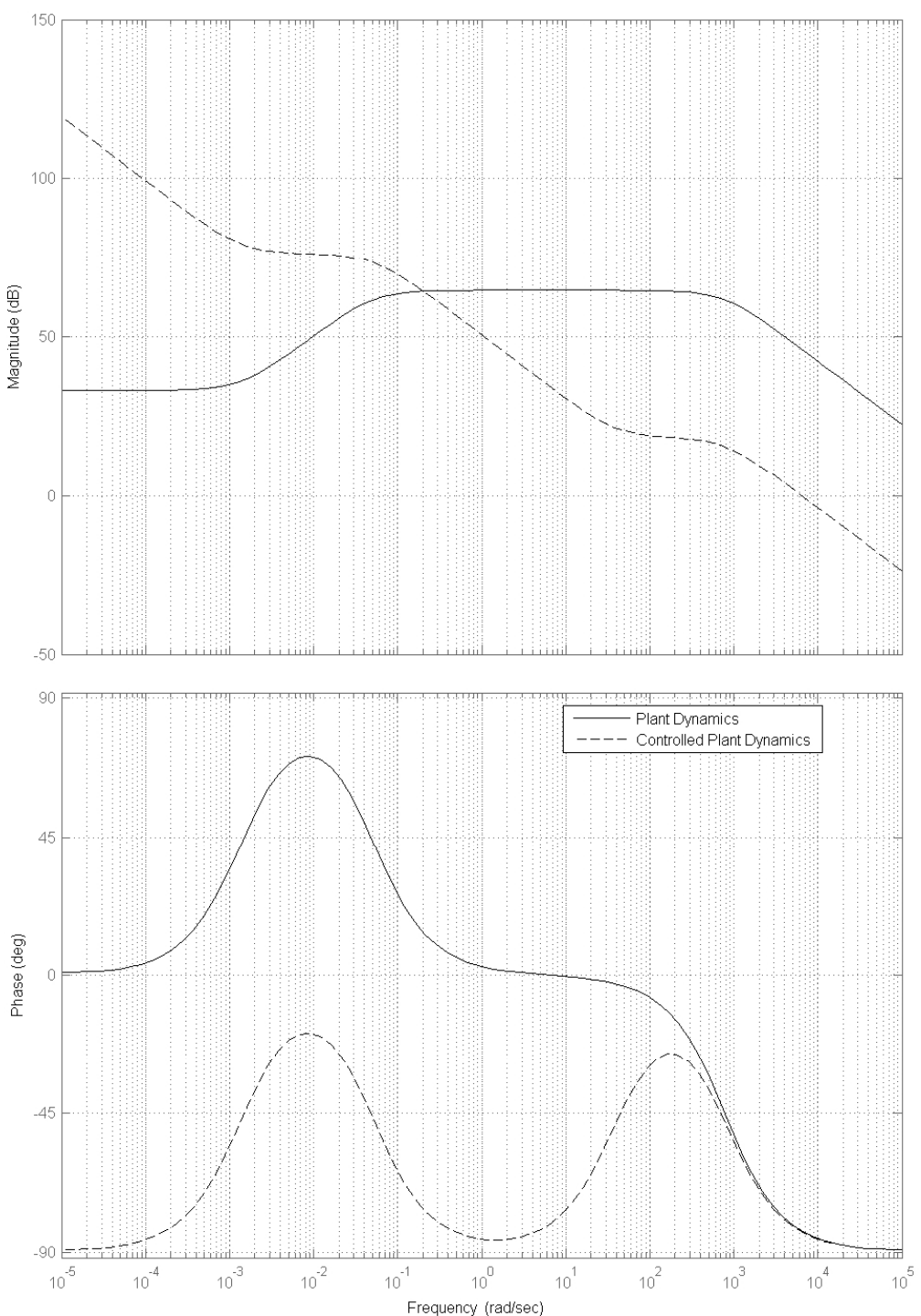

Figure 4: Controlled and uncontrolled open loop system dynamics for the current control loop 
Bode Diagram
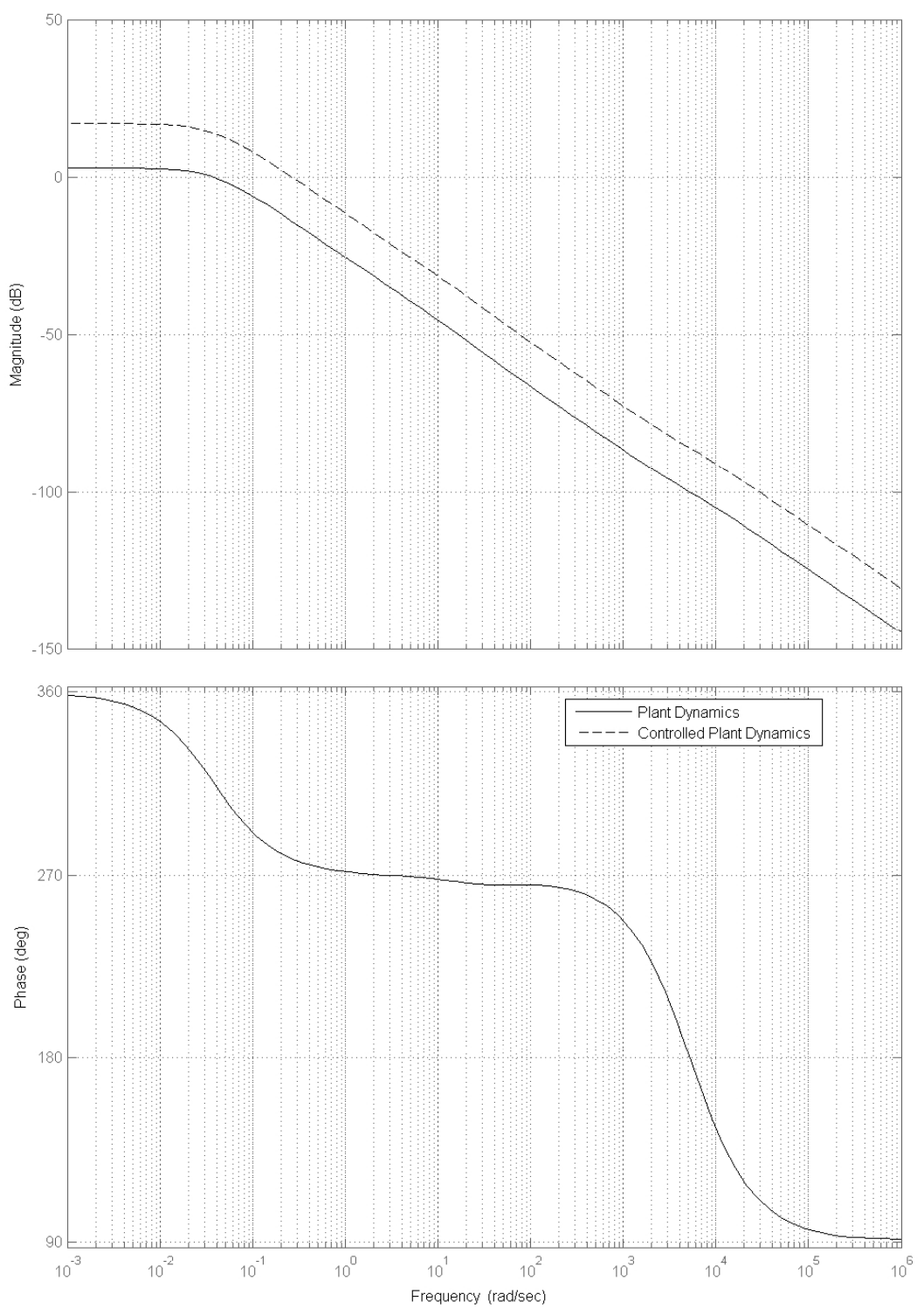

Figure 5: Controlled and uncontrolled open loop system dynamics for the voltage control loop 


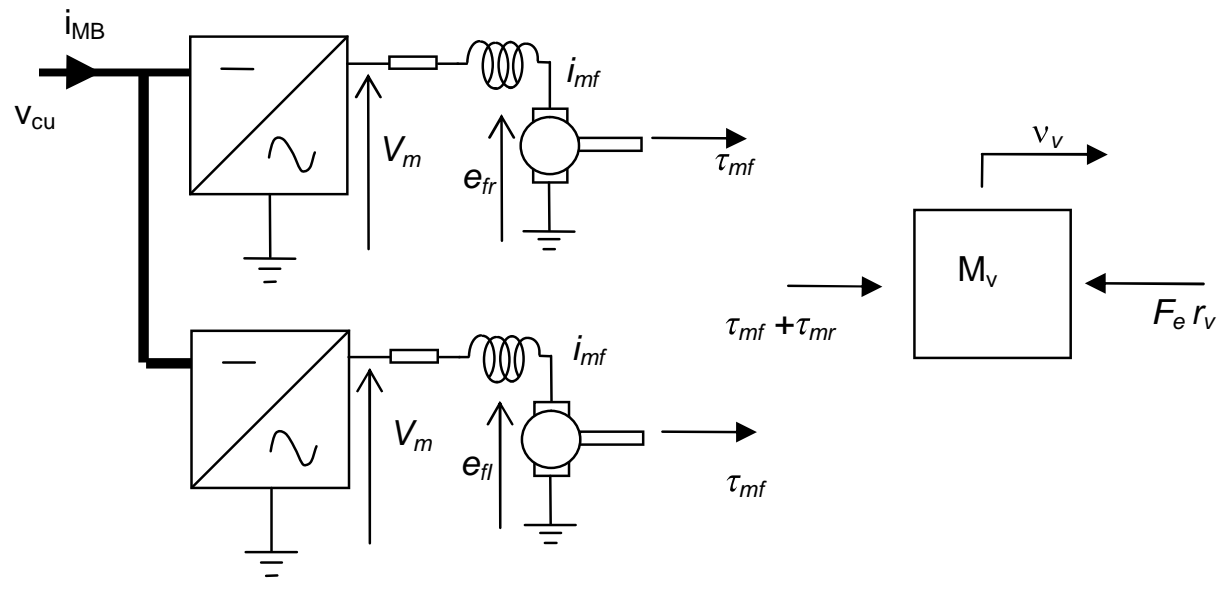

Figure 6: Free body diagram for the HEV powertrain model 


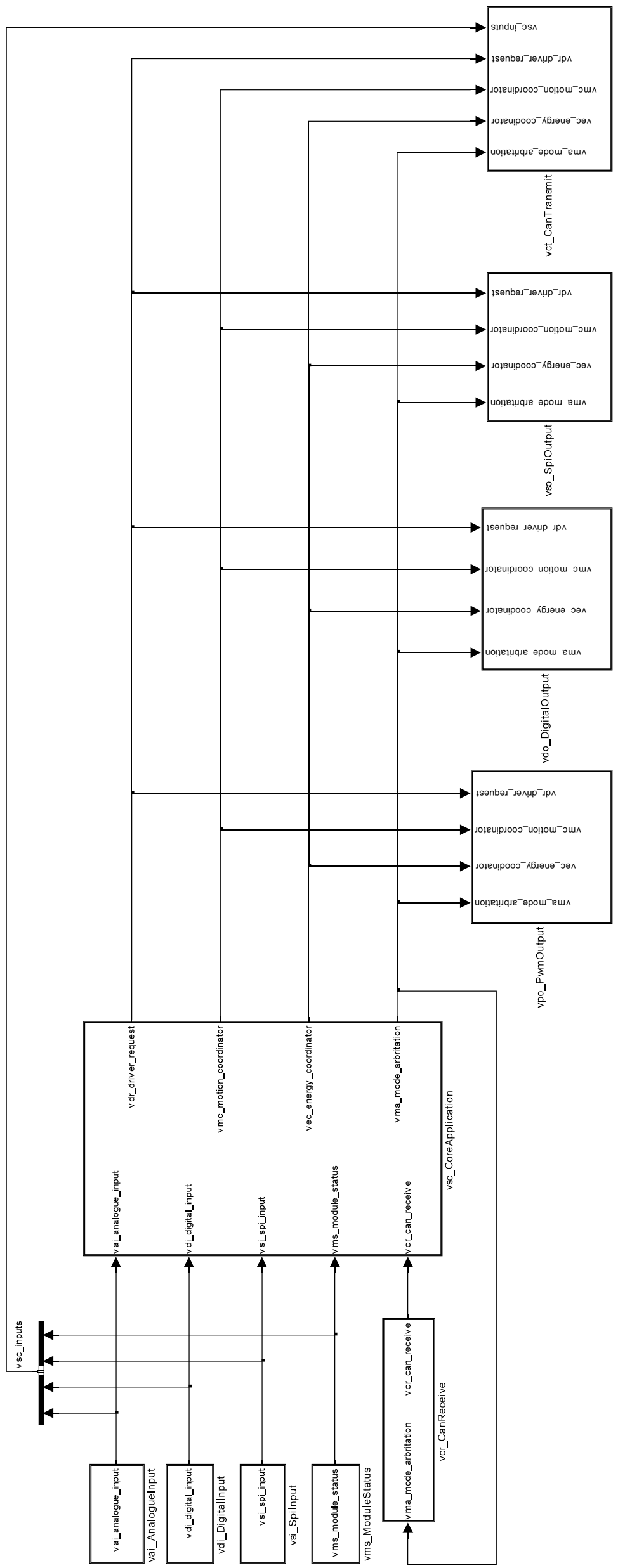



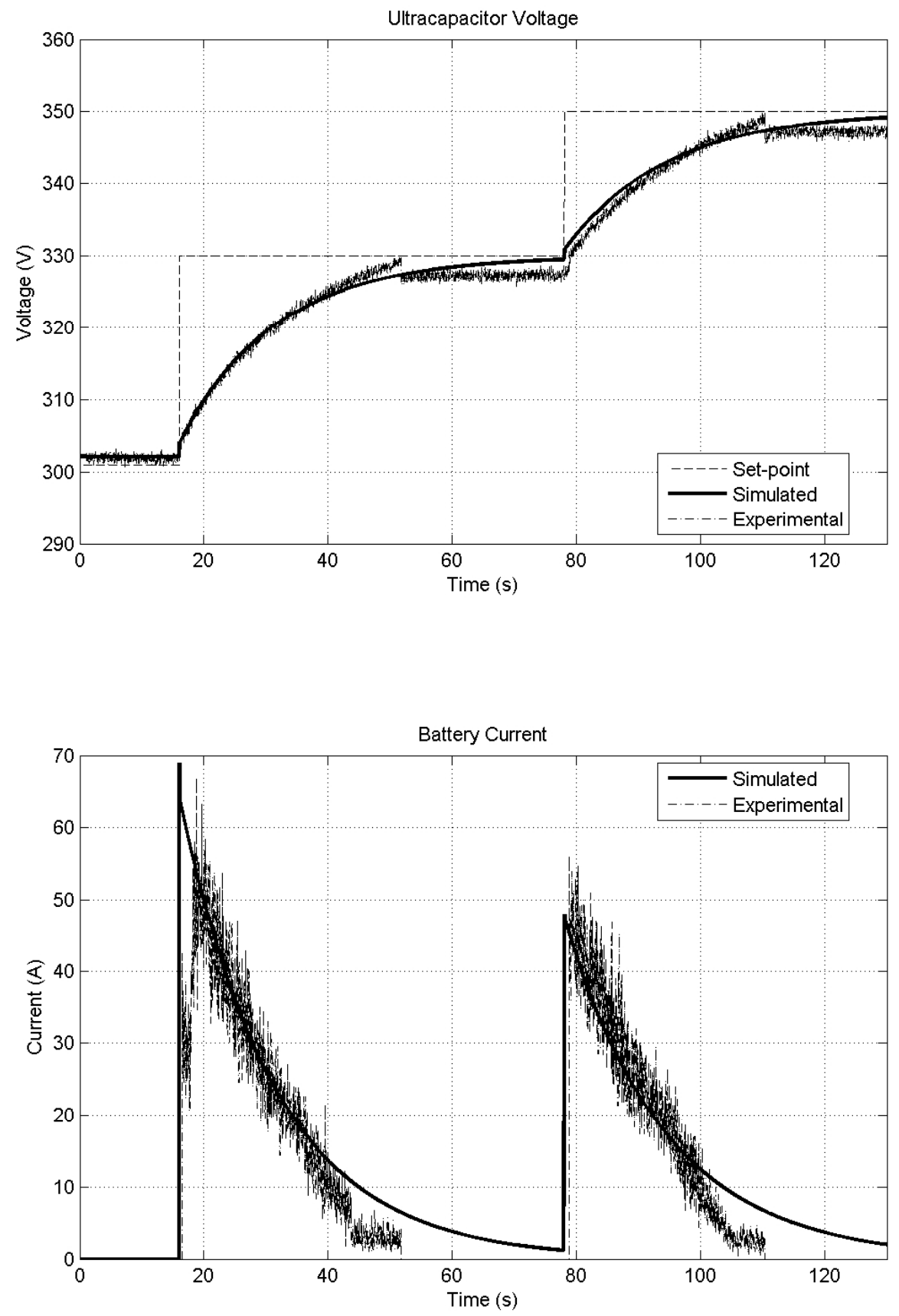

Figure 8: Set-point response of the power management strategy 

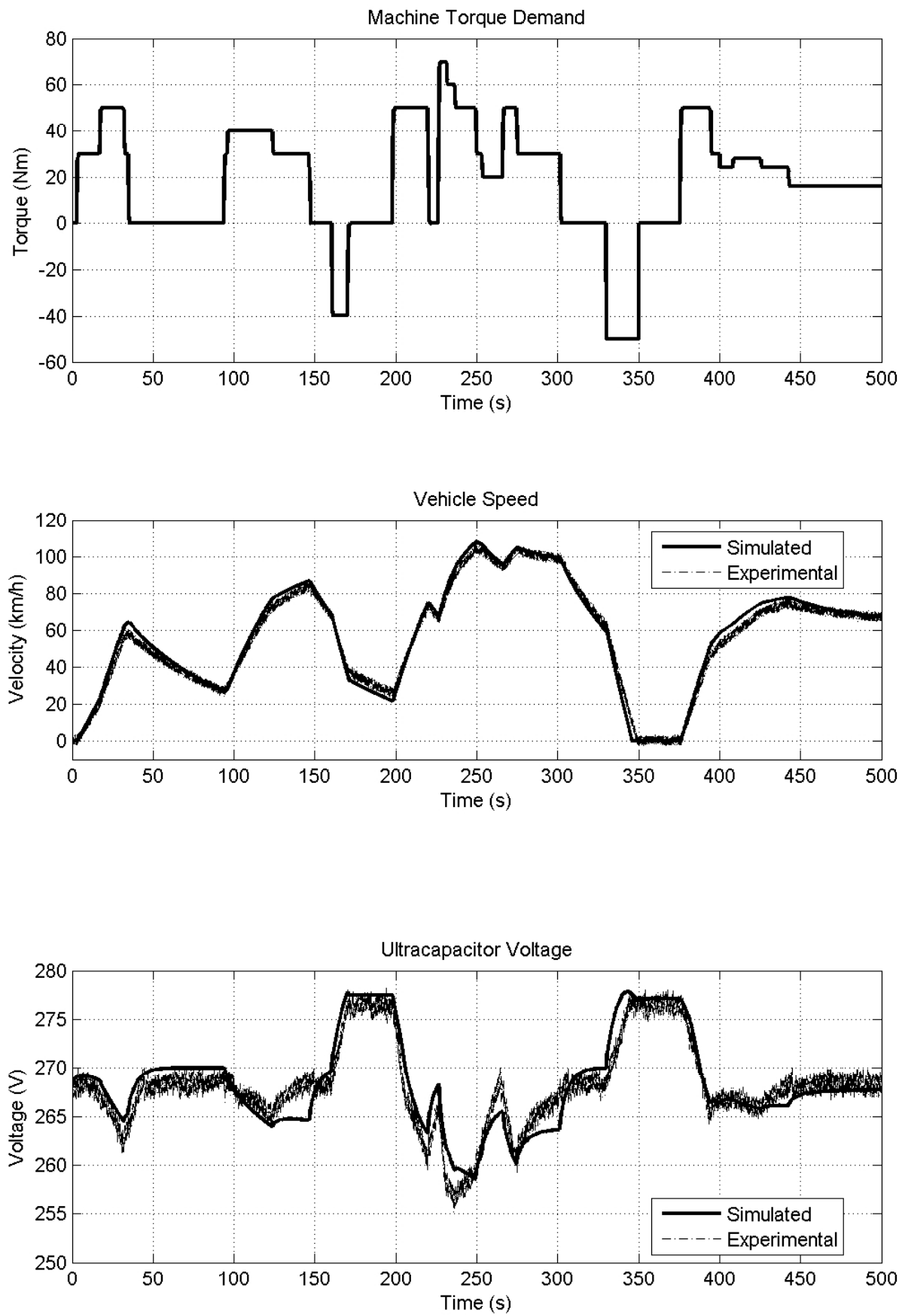

Figure 9: Disturbance rejection characteristics of the power management strategy 

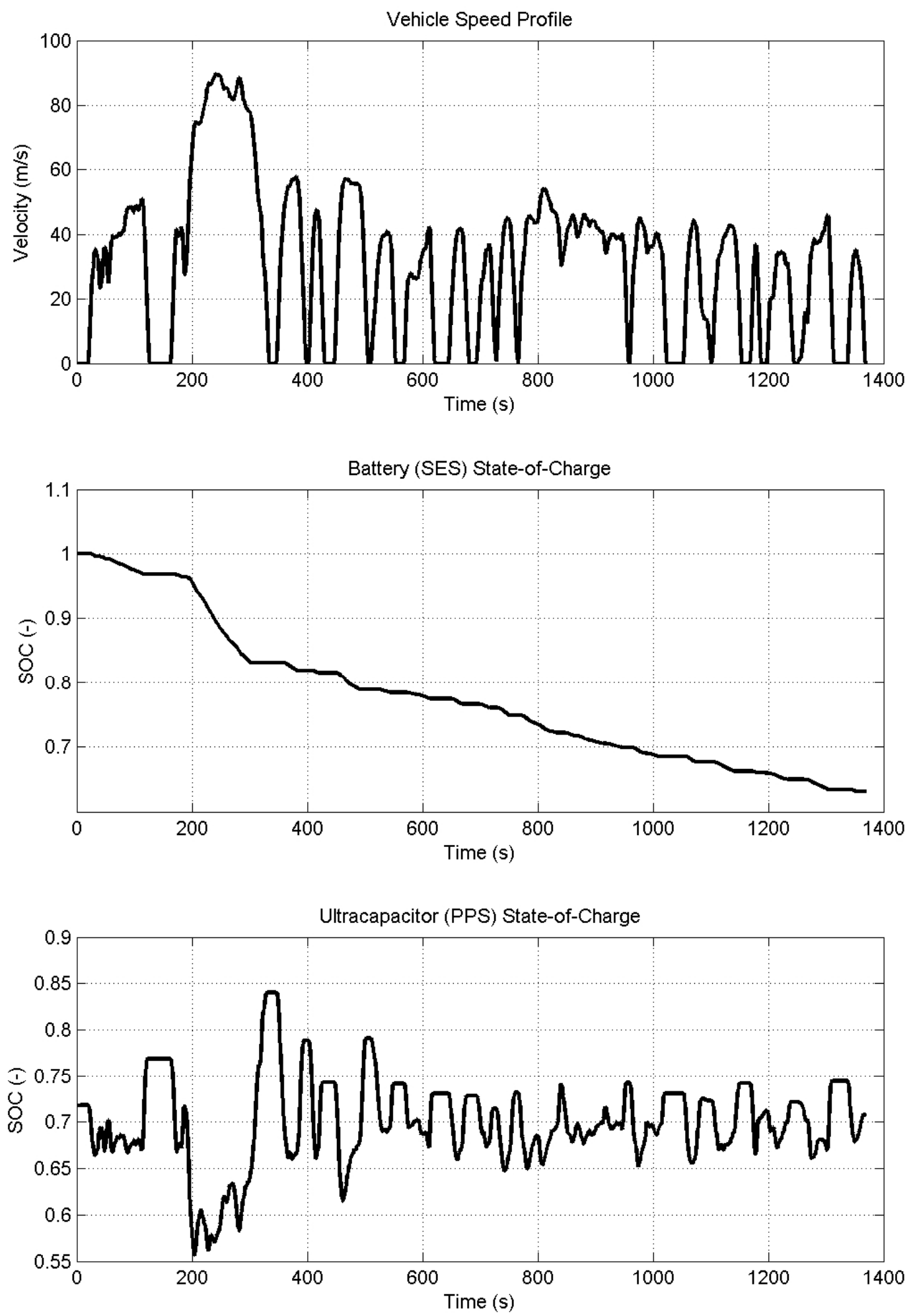

Figure 10: Drive-cycle performance of the HEV over the UDDS drive-cycle 

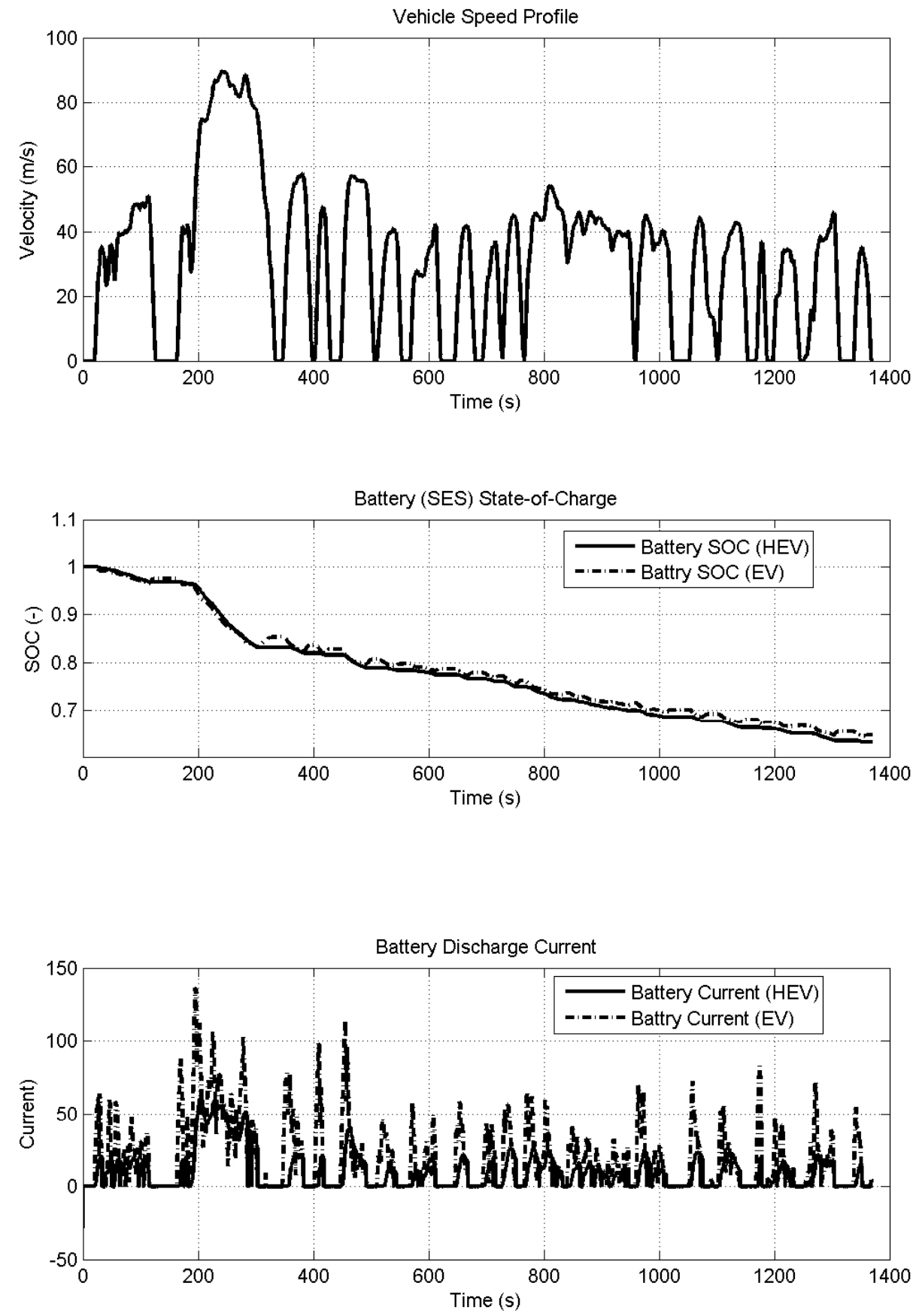

Figure 11: A Comparison of HEV and EV performance over the UDDS drive-cycle 